Agricultural Journal 14 (5): 104-108, 2019

ISSN: 1816-9155

(C) Medwell Journals, 2019

\title{
Performance of Tef [Eragrostis Tef (Zucc.) Trotter] Genotypesin the Non-Traditional Tef Growing Area, Western Ethiopia
}

\author{
${ }^{1}$ Misgana Merga, ${ }^{1,2}$ Alemu Dabi and ${ }^{1}$ Addisu Dereje \\ ${ }^{1}$ Ethiopian Institute of Agricultural Research, Assosa Agricultural Research Center, \\ Assosa, Ethiopia \\ ${ }^{2}$ Ethiopian Institute of Agricultural Research, Kulumsa Agricultural Research Center, \\ Assosa, Ethiopia
}

\begin{abstract}
Cereal is very important crop for human consumption in the world. Among the cereal crops, tef is one of the most popular and staple crop that originated and highly diversified in Ethiopia. The demand is very high in the country and it needs production expansion to the area where tef is not primary grown. The current study was consists of forty-nine tef genotypes were conducted by using simple lattice design at Assosa, Western Ethiopia for two consecutive cropping seasons (2016 and 2017) to evaluate the performance of tef genotypes for the non-traditional tef growing area particularly Assosa, Ethiopia. The analysis of variance indicated that there was high $(\mathrm{p} \leq 0.01)$ significant difference among tested tef genotypes for days to heading, plant height, panicle length, culm length, grain yield and harvest index. From the mean performance of genotypes, the maximum grain yield of 14.70, 14.33, 13.49 and $13.31 \mathrm{kgha}^{-1}$ were obtained from G-12, G-1, G-37 and G-19. These genotypes were showed superior performance in grain yield and they could be recommended for further evaluating under the next breeding phase of variety trail.
\end{abstract}

$\underline{\text { Key words: Tef, grain yield, shoot biomass, staple crop, variety }}$

\section{INTRODUCTION}

Crop like cereal is very important for human consumption in the world. Among cereal crops tef is one of the most popular and staple crops originated and highly diversified in Ethiopia. It has several advantages such as adapted to diverse a gro-ecological zones which are marginal to most of other crops (Assefa et al., 1999), excellent in nutritional contents and serve as staple food crop for Ethiopians (Bultosa et al., 2002), very important in case of health aspect, since, its free of gluten (Spaenij-Dekking et al., 2005), its straw is highly nutritious and more palatable for livestock (Alemayehu, 2001) and also sources of income for most of the farmers (Hauenstein, 2015), thus why tef is widely acceptable in Ethiopia.

In Ethiopia during 2016/17 main cropping season, tef was covered over 3 million ha of land and 5 million tons of grain was produced (CSA., 2017). In case of productivity, it is low which is estimated to 1.6 tonsha $^{-1}$. The demand is still beyond to the production. On the other hand, the population growth of Ethiopia is radically increased. From 18 million people in 1950, it becomes increased to about 108 million in 2017 (https://country meters.info/en/Ethiopia). This has been a critical impact on the availability of food and most of the people in the country are in-secured with food. According to FAO et al. (2015) report, 32\% of the total population in Ethiopia is estimated to have been undernourished in 2014. One of a potential food cereal crops is tef which is widely grown and able to provide over two-thirds of nutrition in the Ethiopian diet. It's grain is serve about 50 million inhabitants $(60 \%$ of the total population) accounting for $14 \%$ of all calories consumed (Abraham, 2015). So, over 60\% of tef is directly consumed by farm households and consequently plays a crucial role in food security (Hauenstein, 2015). Therefore, improving the productivity of the crops through breeding and also increasing the production of potential food crops like tef is very important in order to feed these people.

Thus, one of the government directions is expanding the cultivation of tef to the non-traditional tef growing are a which has the largest marginal and cultivation land such as Benishangul Gumuz region and then increasing the production of tef in the country. Prior to do this, performance evaluation of tef materials to this area is primary important duties that given to the research institution. Therefore, considering such phenomena the current study was conducted to evaluate some of tef genotypes for the a gro-ecology of Assosa and then identify the most performed genotypes for the next tef breeding research.

Corresponding Author: Misgana Merga, Ethiopian Institute of Agricultural Research, Assosa Agricultural Research Center, Assosa, Ethiopia 
Agric. J., 14 (5): 104-108, 2019

Table 1: Description of tef genotypes used in the experiment

\begin{tabular}{|c|c|c|c|c|c|}
\hline Genotypes & Pedigree/Crosses & Source & Genotypes & Pedigree/Crosses & Source \\
\hline$\overline{\mathrm{G}-1}$ & Kaymurrx3774-13(RIL-173) & DZARC & G-26 & Kaymurri x 3774-13(RIL-7) & $\overline{\text { DZARC }}$ \\
\hline G-2 & Kaymurrix3774-13(RIL-202) & DZARC & G-27 & GA-10-3XKaymurii(RIL-257) & DZARC \\
\hline G-3 & GA-10-3XKaymurri(RIL-275) & DZARC & G-28 & DZ-Cr-387XGA-10-3( RIL-181) & DZARC \\
\hline G-4 & GA-10-3XKaymurri(RIL-192) & DZARC & $\mathrm{G}-29$ & GA-10-3XKaymurii(RIL-186) & DZARC \\
\hline G-5 & GA-10-3XKaymurri(RIL-171) & DZARC & G-30 & DZ-Cr-387XGA-10-3( RIL-193) & DZARC \\
\hline G-6 & GA-10-3XKaymurri(RIL-261) & DZARC & G-31 & GA-10-3XKaymurii(RIL-263) & DZARC \\
\hline G-7 & GA-10-3XKaymurri(RIL-273) & DZARC & G-32 & GA-10-3XKaymurii(RIL-143) & DZARC \\
\hline G-8 & Kaymurri x3774-13(RIL-147) & DZARC & G-33 & Kaymurrix3774-13(RIL-215) & DZARC \\
\hline G-9 & GA-10-3XKaymurri(RIL-248) & DZARC & G-34 & DZ-Cr-387XGA-10-3( RIL-156) & DZARC \\
\hline G-10 & Kaymurrix3774-13(RIL-71) & DZARC & G-35 & DZ-Cr-387XGA-10-3( RIL-154) & DZARC \\
\hline G-11 & Kaymurrix3774-13(RIL-45) & DZARC & G-36 & DZ-Cr-387XGA-10-3( RIL-212) & DZARC \\
\hline G-12 & Kaymurrix3774-13(RIL-72) & DZARC & G-37 & Kaymurrix3774-13(RIL-220) & DZARC \\
\hline G-13 & Kaymurrix3774-13(RIL-87) & DZARC & G-38 & KaymurriX3774-13(RIL-110) & DZARC \\
\hline G-14 & Kaymurrix3774-13(RIL-133) & DZARC & G-39 & KaymurriX3774-13(RIL-218) & DZARC \\
\hline G-15 & Kaymurrix3774-13(RIL-66) & DZARC & $\mathrm{G}-40$ & GA-10-3XKaymurri(RIL-9) & DZARC \\
\hline G-16 & Kaymurrix3774-13(RIL-10) & DZARC & $\mathrm{G}-41$ & GA-10-3XKaymurri(RIL-12) & DZARC \\
\hline G-17 & Kaymurrix3774-13(RIL-80) & DZARC & G-42 & KaymurriX3774-13(RIL-136) & DZARC \\
\hline G-18 & Kaymurrix3774-13(RIL-55) & DZARC & G-43 & GA-10-3XKaymurri(RIL NO.146) & DZARC \\
\hline G-19 & Kaymurrix3774-13(RIL-68) & DZARC & $\mathrm{G}-44$ & KaymurriX3774-13(RIL NO.60) & DZARC \\
\hline G-20 & Kaymurrix3774-13(RIL-105) & DZARC & G-45 & GA-10-3XKaymurri(RIL NO.52) & DZARC \\
\hline G-21 & GA-10-3XKaymurri(RIL-241) & DZARC & G-46 & KaymurriX3774-13(RIL NO.58) & DZARC \\
\hline G-22 & kaymurrix3774-13(RIL-144) & DZARC & $\mathrm{G}-47$ & DZ-Cr-387XGA-10-3(RIL NO.72) & DZARC \\
\hline G-23 & DZ-Cr-387XGA-10-3(RIL-168) & DZARC & G-48 & Quncho & DZARC \\
\hline G-24 & GA-10-3XKaymurii(RIL-196) & DZARC & G-49 & Boset & DZARC \\
\hline G-25 & DZ-Cr-387XGA-10-3( RIL-217) & DZARC & & & \\
\hline
\end{tabular}

G: Genotype

\section{MATERIALS AND METHODS}

Experimental site and planting: The experiment was conducted during 2016 and 2017 main cropping season at the field of Assosa Agricultural Research Center (AsARC) in Benishangul Gumuz region, Ethiopia. Its altitude is $1547 \mathrm{~m}$ above sea level (masl). Assosa district receive an average annual rainfall of $1275 \mathrm{~mm}$. The minimum and maximum temperatures are 17 and $28^{\circ} \mathrm{C}$, respectively. The dominant soil types of this area are Nitosols and Fluvisols with a soil $\mathrm{pH}$ range of 5.0-6.0. For this study, a total of 49 tef, genotypes along with two standard checks, Quncho and Boset were used. They were kindly obtained from Debre Zeit Agricultural Research Center (Table 1).

Experimental design and management: The experiment was conducted by using $7 \times 7$ simple lattice design with two replications. Each plot was consists of five rows of $2 \mathrm{~m}$ length with $0.2 \mathrm{~m}$ inter-row distance $\left(1 \times 2 \mathrm{~m}=2 \mathrm{~m}^{2}\right)$. The distance between plots, blocks and replications were $0.5,1$ and $1.5 \mathrm{~m}$, respectively. The seed rate of $15 \mathrm{kgha}^{-1}$ was drilled by hand within the prepared rows. Fertilizer rate of $46 \mathrm{kgha}^{-1} \mathrm{P}_{2} \mathrm{O}_{5}$ in the form of NPS was applied at the time of sowing and $23 \mathrm{kgha}^{-1}$ $\mathrm{N}_{2}$ in the form of urea was applied in split form (i.e., half of recommended $\mathrm{N}_{2}$ at sowing and the left was applied 30-35 days after sowing). Hand weeding was performed frequently based on the extents of weed.

Data collected: Data were collected based on plot and individual plant bases. Plot based data were days to seedling emergence, days to heading, days to maturity, grain filling period above ground biomass, grain yield, harvest index and lodging index using the method of Caldicott and Nuttall (1997). Whereas panicle length, plant height and culm length data were taken on individual plant basis from five randomly selected and pre-tagged plants of the central rows of each plot and its average values were used for data analysis.

Statistical analyses: Statistical analysis was carried out as per the procedure of simple lattice design and all the recorded data were subjected to Analysis of Variance (ANOVA) and the mean separation were tested by using Least Significant Difference (LSD) at the levels of probability $5 \%$ as per the method of Gomez and Gomez (1984) using R (Version 3.1.3) computer package.

\section{RESULTS AND DISCUSSION}

Analysis of variance: Analysis of variance for all traits was presented in Table 2 . As the result indicated, highly $(\mathrm{p} \leq 0.01)$ significant differences were observed among evaluated tef genotypes for days to heading, plant height, panicle length, culm length above ground biomass, grain yield and harvest index; significant $(\mathrm{p} \leq 0.05)$ for only lodging index (Table 3$)$. Besides, a significant $(\mathrm{p} \leq 0.05)$ year variation also observed in all of the traits except plant height, lodging index and grain yield. On the other hand, genotype by year interaction did induce a significant variation in days to heading and maturity, grain filling period, panicle length above graound biomass and grain yield. This indicates the different tef genotypes 
Agric. J., 14 (5): 104-108, 2019

Table 2: Mean squares from combined analysisfor ten traits of 49 tef genotypes evaluated at Assosa in 2015-2017 cropping seasons

\begin{tabular}{llllllllllll} 
Source & df & DTH & DTM & GFP & PH & PL & CL & LI & ABM & GY & HI \\
\hline Year & 1 & $9674.13^{* *}$ & $50336.13^{* *}$ & $15876^{* *}$ & 85.17 & $34.14^{*}$ & $227.15^{* *}$ & 18.37 & $8957.27^{* *}$ & 9.35 & $948.07^{* *}$ \\
Rep (Year) & 2 & $16.74^{* *}$ & 0.62 & $18.37^{*}$ & 8.49 & 3.72 & 23.45 & 112.36 & 156.25 & 4.38 & 27.39 \\
Block (Year) & 12 & 3.33 & 4.36 & 2.36 & 39.67 & 6.56 & 25.6 & 174.96 & 215.23 & 1.42 & 32.41 \\
Block (Rep) & 6 & 4.26 & 3.27 & 0.75 & 42.71 & 12.2 & 15.47 & 101.45 & 106.25 & $15.32^{* *}$ & 24.37 \\
Genotype & 48 & $5.21^{* *}$ & 4.39 & 5.37 & $107.56^{* *}$ & $42.41^{* *}$ & $43.83^{* *}$ & $146.99^{*}$ & $378.36^{* *}$ & $17.40^{* *}$ & $63.43^{* *}$ \\
Year*Genotype & 48 & $2.50^{* *}$ & $6.01^{*}$ & $6.93^{*}$ & 31.49 & $11.67 * *$ & 12.9 & 72.21 & $358.93^{* *}$ & $8.53^{*}$ & 41.61 \\
$\mathrm{R}^{2}$ & & 0.99 & 0.99 & 0.98 & 0.78 & 0.87 & 0.76 & 0.71 & 0.78 & 0.81 & 0.74 \\
CV\% & & 2.9 & 2.37 & 4.49 & 5.81 & 6.53 & 6.91 & 14.59 & 24.87 & 21.99 & 28.72 \\
Mean & & 37.01 & 81.51 & 44.5 & 95.05 & 36.66 & 58.38 & 64.14 & 55.84 & 10.13 & 19.41 \\
\hline
\end{tabular}

df: Degree of freedom, DTH: Days to Heading, DTM: Days to Maturity, GFP: Grain Filling Period, PH: Plant Height, PL: Panicle Length, CL: Culm

Length, LI: Lodging Index, ABM: Above Ground Biomass, GY: Grain Yield, HI: Harvest Index, CV\%: Coefficient of Variation

Table 3: Mean performance for ten traits of 49 tef genotypes evaluated at Assosain 2015-2017 cropping seasons

\begin{tabular}{|c|c|c|c|c|c|c|c|c|c|c|c|c|}
\hline $\begin{array}{l}\text { Genotype } \\
\#\end{array}$ & Pedigrees/Crosses & DTH & DTM & GFP & $\mathrm{PH}$ & PL & $\mathrm{CL}$ & LI & $\begin{array}{l}\text { SBM } \\
\left(\text { tha }^{-1}\right)\end{array}$ & $\begin{array}{l}\text { GY } \\
\left(\mathrm{kgha}^{-1}\right)\end{array}$ & $\mathrm{HI}(\%)$ & $\begin{array}{l}\text { Yield } \\
\text { advantage } \\
\text { over } \\
\text { standard } \\
\end{array}$ \\
\hline$\overline{\mathrm{G}-1}$ & Kaymurrix3774-13(RIL-173) & 37.75 & 81.75 & 44 & 93.45 & 36.5 & 56.95 & 70.4 & 66.25 & 14.325 & 21.938 & 31.87 \\
\hline G-2 & Kaymurrix3774-13(RIL-202) & 37 & 83.5 & 46.5 & 90.6 & 36 & 54.6 & 60.75 & 56.25 & 9.225 & 18.513 & -15.08 \\
\hline G-3 & GA-10-3XKaymurri(RIL-275) & 36.25 & 80.5 & 44.25 & 93.45 & 34 & 59.45 & 62.5 & 55 & 12.538 & 23.62 & 15.42 \\
\hline G-4 & GA-10-3XKaymurri(RIL-192) & 35.5 & 80.25 & 44.75 & 89.8 & 32.3 & 57.5 & 76 & 48.75 & 9.888 & 21.865 & -8.98 \\
\hline G-5 & GA-10-3XKaymurri(RIL-171) & 37.75 & 82 & 44.25 & 75 & 32.15 & 42.85 & 64.25 & 25 & 5.688 & 31.275 & -47.64 \\
\hline G-6 & GA-10-3XKaymurri(RIL-261) & 38.5 & 81 & 42.5 & 97.55 & 38.75 & 58.8 & 67.6 & 55 & 11.213 & 22.643 & 3.22 \\
\hline G-7 & GA-10-3XKaymurri(RIL-273) & 35.25 & 80.25 & 45 & 89.7 & 30.1 & 59.6 & 67.75 & 57.5 & 12.363 & 20.77 & 13.81 \\
\hline G-8 & Kaymurri x3774-13(RIL-147) & 37.25 & 82.25 & 45 & 95.9 & 39.35 & 56.55 & 61.5 & 51.25 & 8.7 & 17.75 & -19.91 \\
\hline G-9 & GA-10-3XKaymurri(RIL-248) & 37.5 & 82.5 & 45 & 99.75 & 37.2 & 62.55 & 69 & 56.25 & 13.075 & 23.47 & 20.36 \\
\hline G-10 & Kaymurrix3774-13(RIL-71) & 37.5 & 81.75 & 44.25 & 94.95 & 41.75 & 53.2 & 73.5 & 52.5 & 12.375 & 24.155 & 13.92 \\
\hline G-11 & Kaymurrix3774-13(RIL-45) & 36 & 82 & 46 & 94.05 & 37 & 57.05 & 60 & 60 & 9.225 & 15.218 & -15.08 \\
\hline $\mathrm{G}-12$ & Kaymurrix3774-13(RIL-72) & 37 & 81.5 & 44.5 & 93.9 & 36.55 & 57.35 & 61.75 & 70 & 14.7 & 22.135 & 35.32 \\
\hline G-13 & Kaymurrix3774-13(RIL-87) & 38 & 82.5 & 44.5 & 96.25 & 36.6 & 59.65 & 52.5 & 55 & 10.825 & 20.285 & -0.35 \\
\hline G-14 & Kaymurrix3774-13(RIL-133) & 36.25 & 80.25 & 44 & 90.75 & 35.25 & 55.5 & 54.75 & 47.5 & 8.4 & 20.065 & -22.67 \\
\hline G-15 & Kaymurrix3774-13(RIL-66) & 38.75 & 82.5 & 43.75 & 102.15 & 41.8 & 60.35 & 65 & 71.25 & 8.688 & 12.648 & -20.02 \\
\hline G-16 & Kaymurrix3774-13(RIL-10) & 36.75 & 82.25 & 45.5 & 94.9 & 35.65 & 59.25 & 51.45 & 58.75 & 10.55 & 18.048 & -2.88 \\
\hline G-17 & Kaym & 38.25 & 82.75 & 44.5 & 94.45 & 36.75 & 57.7 & 58.25 & 51.25 & & 14.7 & -34.98 \\
\hline G-18 & Kaymurrix3774-13(RIL-55) & 35.75 & 80.5 & 44.75 & 96.6 & 37.65 & 58.95 & 58.75 & 58.75 & 8.8 & 15.753 & -18.99 \\
\hline G-19 & Kaymurrix3774-13(RIL-68) & 38.25 & 82.5 & 44.25 & 97.85 & 38.45 & 59.4 & 71 & 58.75 & 13.313 & 23.765 & 22.55 \\
\hline G-20 & 774-13(RIL-105) & 37.5 & 80.75 & 43.25 & 90.75 & 35.1 & 55.65 & 65.25 & 50 & 12.125 & 25.018 & 11.62 \\
\hline G-21 & GA-10-3XKaymurri(RIL-241) & 38 & 82.5 & 44.5 & 93.4 & 38.7 & 54.7 & 66.5 & 72.5 & 11.788 & 20.44 & 8.52 \\
\hline G-22 & kaymurrix3774-13(RIL-144) & 38.25 & 83.25 & 45 & 101.9 & 38.2 & 63.7 & 62 & 57.5 & 7.988 & 14.108 & -26.47 \\
\hline G-23 & DZ-Cr-387 X GA-10-3(RIL-168) & 35.5 & 80.25 & 44.75 & 92.35 & 37 & 55.35 & 66.75 & 50 & 10.463 & 21.028 & -3.68 \\
\hline G-24 & GA-10-3 X Kaymurii(RIL-196) & 35.5 & 82.75 & 47.25 & 89.75 & 32.6 & 57.15 & 54.5 & 51.25 & 11.963 & 23.835 & 10.13 \\
\hline G-25 & DZ-Cr-387 X GA-10-3( RIL-217) & 39.75 & 83 & 43.25 & 102.75 & 41.65 & 61.1 & 73.5 & 60 & 8 & 13.543 & -26.36 \\
\hline G-26 & Kaymurri x 3774-13(RIL-7) & 36 & 81.75 & 45.75 & 98.4 & 36.15 & 62.25 & 62.55 & 70 & 12.325 & 17.93 & 13.46 \\
\hline G-27 & GA-10-3X Kaymurii(RIL-257) & 35.25 & 80.5 & 45.25 & 93.45 & 34.6 & 58.85 & 61.5 & 52.5 & 9.438 & 18.018 & -13.12 \\
\hline G-28 & 7 X GA-10-3( RIL-181) & 34.75 & 79.75 & 45 & 96.95 & 34.85 & 62.1 & 64.75 & 51.25 & 25 & 21.355 & 0.57 \\
\hline G-29 & GA-10-3X Kaymurii(RIL-186) & 36.25 & 81.5 & 45.25 & 94.55 & 33.45 & 61.1 & 79 & 77.5 & 13.075 & 20.27 & 20.36 \\
\hline G-30 & DZ-Cr-387 X GA-10-3( RIL-193) & 35.5 & 84.25 & 48.75 & & 36.75 & 56.4 & 68 & 50 & & 25.72 & 18.87 \\
\hline G-31 & GA-10-3X Kaymurii(RIL-263) & 36.75 & 81.5 & 44.75 & 99.95 & 38.7 & 61.25 & 69.2 & 60 & 9.825 & 16.383 & -9.56 \\
\hline G-32 & GA-10-3X Kaymurii(RIL-143) & 38.5 & 80.75 & 42.25 & 96.2 & 40.8 & 55.4 & 68.5 & 93.75 & 10.75 & 14.73 & -1.04 \\
\hline G-33 & Kavmurrix 3774-13(RU -215) & 37.25 & 80 & 42.75 & 93.95 & 33. & 60.45 & 66.65 & 52.5 & 10.225 & 19.398 & -5.87 \\
\hline G-34 & DZ-Cr-387X GA-10-3( RIL-156) & 37.75 & 81.5 & 43.75 & 111.9 & 45.8 & 66.1 & 70.25 & 51.25 & 9.625 & 18.245 & -11.40 \\
\hline G-35 & DZ-Cr-387X GA-10-3( RIL-154) & 35.25 & 81.5 & 46.25 & 89.8 & 35.8 & 54 & 71 & 46.25 & 9.713 & 22.76 & -10.59 \\
\hline G-36 & -10-3( RIL-212) & 38.25 & 82.5 & 44.25 & 104.3 & 43 & 60.5 & 60.75 & 61.25 & & 13.928 & -25.55 \\
\hline G-37 & 3774-13(RIL-220) & 37.75 & 80.75 & 43 & 96 & 37.35 & 58.65 & 66.25 & 60 & 13.488 & 22.94 & 24.16 \\
\hline G-38 & KaymurriX3774-13(RIL-110) & 37.5 & 81 & 43.5 & 92 & 33.1 & 58.9 & 49.75 & 51.25 & 6.95 & 15.545 & -36.02 \\
\hline G-39 & X3774-13(RIL-218) & 36 & 79.25 & 43.25 & 89.5 & & 57.65 & 62.35 & 45 & 8.5 & 18.795 & -21.75 \\
\hline G-40 & -3XKaymurri & 37 & 80.25 & 43.25 & 93.4 & 31.75 & 61.65 & 59 & 47.5 & 6.263 & 13.998 & -42.35 \\
\hline G-41 & GA-10-3XKaymurri(RIL-12) & 37 & 80.75 & 43.75 & 96.3 & 35.9 & 60.4 & 66.25 & 58.75 & 12.663 & 22.285 & 16.57 \\
\hline G-42 & Y $277112(\mathrm{DU} 126)$ & 37.5 & 80.5 & 43 & 94.8 & 33 & 617 & 56.9 & 47.5 & 7.8 & & -28.20 \\
\hline G-43 & GA-10-3XKaymurri(RIL NO.146) & 36.5 & 80.25 & 43.75 & 91.4 & 34.3 & 57.1 & 51.75 & 40 & 8.713 & 23.345 & -19.79 \\
\hline G-44 & X3774-13(RIL NO.60) & 37 & 81 & 44 & 97.7 & 39.8 & 57.9 & 55.75 & 61.25 & 9.4 & 598 & -13.47 \\
\hline G-45 & 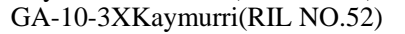 & 37.25 & 79. & 42.25 & 94.4 & 40.2 & 54.2 & 76 & 61.25 & 10.138 & 16.663 & -6.67 \\
\hline G-46 & KaymurriX3774-13(RIL NO.58) & 38.75 & 83.25 & 44.5 & 91.15 & 34.6 & 56.55 & 57.65 & 38.75 & 7.075 & 20.483 & -34.87 \\
\hline G-47 & DZ-Cr-387XGA-10-3(RIL NO.72) & 35.5 & 83.5 & 48 & 98.35 & 37.75 & 60.6 & 71.75 & 52.5 & 8.25 & 16.138 & -24.05 \\
\hline G-48 & Quncho & 39 & 82 & 43 & 105.8 & 41.05 & 64.75 & 64 & 56.25 & 6 & 12.86 & -44.77 \\
\hline G-49 & Boset & 35.25 & 81.25 & 46 & 91.95 & 34.45 & 57.5 & 68.25 & 53.75 & 10.863 & 20.163 & - \\
\hline Minim & & & 79.25 & 42.25 & 75 & 30.1 & 42.85 & 49.75 & 25 & & & \\
\hline Maxin & & 39.75 & 84.25 & 48.75 & 111.9 & 45.8 & 66.1 & 79 & 93.75 & 14.7 & 31.275 & \\
\hline Mean & & 37.04 & 81.51 & 44.47 & 95.11 & 36.71 & 58.40 & 64.06 & 55.89 & 10.11 & 19.40 & \\
\hline LSD 0.05 & & 1.51 & 2.72 & 2.82 & 7.77 & 3.37 & 5.68 & 13.18 & 19.55 & 3.14 & 7.85 & \\
\hline
\end{tabular}

DTH: Days to Heading, DTM: Days to Maturity, GFP: Grain Filling Period, PH: Plant Height, PL: Panicle Length, CL: Culm Length, LI: Lodging Index, ABM: Above Ground Biomass, GY: Grain Yield, HI: Harvest Index 
Agric. J., 14 (5): 104-108, 2019

were performed in different manner in both cropping seasons. The variation in weather condition is always has a primary impact on the crops phenology and growth. The significant variation of grain yield trait is supported by the previous studies by Shiferaw et al. (2012), Abraha et al. (2016) and Plaza et al. (2013).

Mean performance of the genotypes: The maximum day to maturity was 84 days for the genotype G-34 and the least was 79 days for genotype G-3. The mean number of days to heading was 81 day (Table 3). The overall evaluated genotypes at this area are relatively early matured. The ranges of days to maturity was narrower as compared to the previous study by Assefa et al. (2000) who reported 84-100 days to maturity of 320 tef germplasms collected from diverse a gro-ecology of Ethiopia and evaluated at Debrezait and Alem Tena. Hence, the climatic conditions of one area adversely affect the maturity period of crop and thus, most of the materials evaluated in this area were forced to early. The shorter phenology of the genotypes evaluated at this area might be due to the low altitude of the area. Thus, knowing of the phonological features of crop is important to adjusting the time of planting and may be reduces the adverse effects of weather condition (Bedane et al., 2015).

There were high significant difference among genotypes for plant height which was ranged from $75 \mathrm{~cm}$ for G-5 to $111.9 \mathrm{~cm}$ for G-34 with an average mean value of $95 \mathrm{~cm}$. Genotype G-34 was the tallest height of $111.9 \mathrm{~cm}$ followed by variety Quncho $(105.8 \mathrm{~cm})$, G-36 $(104.3 \mathrm{~cm})$ and G-25 $(102.8 \mathrm{~cm})$ while the shortest plant height were found for G-5 $(75 \mathrm{~cm})$. The length of panicle was ranged between 30-45.8 cm with an average mean value of $36.7 \mathrm{~cm}$. The maximum panicle length is for G-34 and the least one is for G-7. Culm length is the difference of plant height and panicle length. Maximum culm length was found for G-34 (66 cm) while the least culm length was for G-5 $(42.8 \mathrm{~cm})$. Most of the time, these three traits have strong positive association with each other's (Merga, 2018; Abraha et al., 2017). Consideration of such plant growth characters during selection is very important as it is helpful to selecting the genotype with relatively withstand lodging.

The highest above ground shoot biomass in tonsha ${ }^{-1}$ were recorded for G-32 (9.4) followed by G-29 (7.75), G-21 (72.5), G-15 (71.25) and G-12 (70) in a descending order. While the least in biomass yield was for G-5 (2.5). The biomass of tef is very crucial which have a comparative importance with grain yield, since, its straw is more palatable for animal and also used for market price (Alemayehu, 2001; Abraham, 2015). Sometimes, an increase in biomass yield may be leads to decrease in grain yield due to its negative association of lodging index (Merga, 2018). So, selecting the genotype which has not very high biomass is important. Big grain yield variation was observed among the genotypes which is ranged from 0.57 (G-5) to 1.47 tonsha $^{-1}$ (G-12). This big variation among genotypes might be mainly due to the genetic potential of the genotypes. The two standard checks, Boset and Quncho were gave 1.086 and 0.6 tonha $^{-1}$, respectively. The top genotype (G-12) has about $35 \%$ of yield advantage over the best standard check, Boset and also relatively better harvest index. Based on the mean value, overall genotypes which have minimum of $10 \%$ yield advantage over the best check were selected and advanced to the next breeding step which is a regional variety trail.

\section{CONCLUSION}

Tef is very important cereal crop which plays a crucial role in the Ethiopian de it. The expansion of its cultivation to the area where tef is not primary grown is useful to increasing the amount of production in the country and also able to improve the gap between demand and production relatively. The results of current study concluded the existence of substantial variability with in evaluated tef genotypes which is an opportunity for the exploitation in tef improvement. Among the evaluated genotypes, the highest mean of grain yield in $\mathrm{kgha}^{-1}$ were obtained from G-12, G-1, G-37 and G-19. These genotypes were showed a superior performance in grain yield of 14.70, 14.33, 13.49 and 13.31, respectively. Those genotypes which have more than $10 \%$ of yield advantage over the best check were selected as interesting genotypes and they are advanced to the next breeding stage being evaluated as a regional variety trail.

\section{REFERENCES}

Abraha, M.T., H. Shimelis, M. Laing and K. Assefa, 2016. Performance of tef [Eragrostis tef (Zucc.) Trotter] genotypes for yield and yield components under drought-stressed and non-stressed conditions. Crop Sci., 56: 1799-1806.

Abraha, M.T., S. Hussein, M. Laing and K. Assefa, 2017. Genetic variation and trait association of tef [Eragrostis tef (Zucc.) Trotter] evaluated under optimal and moisture stressed environments. Aust. J. Crop Sci., 11: 241-247.

Abraham, R., 2015. Achieving food security in Ethiopia by promoting productivity of future world food tef: A review. Adv. Plant. Agric. Res., 2: 86-95.

Alemayehu, R., 2001. TEF: Post-harvest operations. Institute of Agricultural Research Organization, (IARO), Holetta Agricultural Research Center, Holeta Genet, Ethiopia.

Assefa, K., S. Ketema, H. Tefera, H.T. Nguyen and A. Blum et al., 1999. Diversity among germplasm lines of the Ethiopian cereal tef Eragrostis tef (Zucc.) Trotter. Euphytica, 106: 87-97. 
Assefa, K., S. Ketema, H. Tefera, T. Kefyalew and F. Hundera, 2000. Trait diversity, heritability and genetic advance in selected germplasm lines of tef [Emgmstis tef (Zucc.) Trotter]. Hereditas, 133: 29-37.

Bedane, G.M., A.M. Saukuru, D.L. George and M.L. Gupta, 2015. Evaluation of teff [Eragrostis tef (Zucc.) Trotter] lines for agronomic traits in Australia. Aust. J. Crop Sci., 9: 242-247.

Bultosa, G., A.N. Hall and J.R. Taylor, 2002. Physico-chemical characterization of grain tef (Eragrostis tef (Zucc.) Trotter) starch. Starch Starke, 54: 461-468.

CSA., 2017. Agricultural sample survey for 2016/17. Central Statistical Agency, Addis Ababa, Ethiopia.

Caldicott, J.J. and A.M. Nuttall, 1997. A method for the assessment of lodging in cereal crops. J. Nat. Agric. Bot., 15: 88-91.

FAO., IFAD. and WFP., 2015. The state of food insecurity in the world 2015. Proceedings of the Meeting of the International Hunger Targets: Taking Stock of Uneven Progress, (HTTSUP'15), Food and Agriculture Organization of the United Nations, Rome.
Gomez, K.A. and A.A. Gomez, 1984. Statistical Procedures for Agricultural Research. 2nd Edn., John Wiley and Sons Inc., New York, USA., pp: 13-175.

Hauenstein, S., 2015. Assessing the resilience of the tef value chain in Ethiopia. MS.C. Thesis, Department of Environmental Systems Science, ETH Zurich, Zurich, Switzerland.

Merga, M., 2018. Genetic variability of Tef [Eragrostis tef (Zucc.) Trotter] genotypes for acidic soil tolerance in Assosa, Western Ethiopia. M.Sc. Thesis, Hawassa University, Awasa, Ethiopia.

Plaza, S., G.M. Cannarozzi and Z. Tadele, 2013. Genetic and phenotypic diversity in selected genotypes of tef [Eragrostis tef (Zucc.)] Trotter. Afr. J. Agric. Res., 8: 1041-1049.

Shiferaw, W., A. Balcha and H. Mohammed, 2012. Genetic variation for grain yield and yield related traits in tef [Eragrostis tef (Zucc.)Trotter] under moisture stress and non-stress environments. Am. J. Plant Sci., 3: 1041-1046.

Spaenij-Dekking, L., Y. Kooy-Winkelaar and F. Koning, 2005. The Ethiopian cereal tef in celiac disease. N. Engl. J. Med., 353: 1748-1749. 